\title{
Retraction Note: Diacerhein attenuates the inflammatory response and improves survival in a model of severe sepsis
}

\author{
Kelly L Calisto, Angélica C Camacho, Francine C Mittestainer, Bruno M Carvalho, Dioze Guadagnini, \\ José B Carvalheira and Mario J Saad ${ }^{*}$
}

The authors would like to retract this article [1] because it was brought to the Editors' attention that some figures appear to be similar to those within the article and in previous publications [2-11]. The similarity between the figures within this article and previous publications, are specified below. An investigation by The University of Campinas (UNICAMP) in São Paulo, Brazil concluded that there was no evidence of research misconduct. The authors maintain that the similarities do not affect the interpretation or conclusions of their study. The authors accept that the preparation of the figures fell below the standard of publication. They will seek to publish the results in a new manuscript version, with new experiments and figures, corroborating the findings of this work. Author, Jose Carvalheira agreed to the retraction and did not disagree with the wording of the retraction.

Figure 4B (IRS-1) from [1] and Fig. 4C (b-actin) from the same article [1].

Figure 4B (IB:IR) from [1]:

And Fig. 1D (IB:IKKb) from Flores et al. 2012 [2]

And Fig. 2D (IB:IRb) from Flores et al. 2012 [2]

And Fig. 4I (IB: GLUT4) from Prada et al. 2006 [3]

And Fig. 6F (IP:IR/IB:pY) from Flores et al. 2006 [4]

And Fig. 2B (Total AMPK) from Ropelle et al. 2007 [5]

And Fig. 3B (Total p70S6K) from Ropelle et al. 2008 [6]

And Fig. 2C (IB: a-Tubulin) from Ropelle et al. 2009 [7]

And Fig. 2G (IB: JAK2) from Ropelle et al. 2008 [8]

And Fig. 2H (IB: STAT3) from Ropelle et al. 2008 [8]

Figure 4B (IB: AKT) from [1]:

And Fig. 1C (IB: IRS2) from De Souza et al. 2010 [9]

And Fig. 1G (IB: Foxo1) from De Souza et al. 2010 [9]

And Fig. 4C (IB: IRS1) from Prada et al. 2006 [3]

And Fig. 2D (Total AMPK) from Ropelle et al. 2007 [5]

And Fig. 2F (a-Tubulin) from Ropelle et al. 2007 [5]

* Correspondence: msaad@fcm.unicamp.br

Department of Internal Medicine, FCM, State University of Campinas

(UNICAMP), Cidade Universitária Zeferino Vaz, Campinas, SP, Brazil
And Fig. 3A (IB: IKKb) from Oliveira et al. 2011 [10] And Fig. 6L (Total eIF4E) from Ropelle et al. 2008 [6] Figure 4C (IB: IRS-1) from [1], lanes $3-4$ and 7-8 Figure 4C (IB: IRS-1) from [1] lane 5 and lane 6 Figure 5A (IB: p-KKb) from [1], and Fig. 5E (IB: INOS) from Calisto et al. 2010 [11]

Figure 5A (IB: b-Actin) from [1], And Fig. 6A (IB: b-Actin) from the same article [1], And Fig. 7B (IB: b-Actin) from the same article [1] And Fig. 4I (IB: IRS1) from Calisto et al. 2010 [11] Figure 5B (IB: b-Actin) from [1]:

And Fig. 6C (IB: b-Actin) from the same article [1] And Fig 4G (IB: IRS1) from Calisto et al. 2010 [11] And Fig. 6D (IB: b-Actin) from Calisto et al. 2010 [11] Figure 5B (IB: NF-kB) from [1] and Fig. 4I (IB: pIRS1Ser307) from Calisto et al. 2010 [11]

Figure 5C (IB: NF-kB) from [1] and Fig. 3E (IB: pIKK) from Calisto et al. 2010 [11]

Figure 7B (IB: p-PERK) from [1] and Fig. 5F (IB: INOS) from Calisto et al. 2010 [11]

Figure 7C (IB: b-Actin) from [1] and Fig. 4H (IB: IRS1) from Calisto et al. 2010 [11]

Received: 11 August 2016 Accepted: 11 August 2016

Published online: 01 September 2016

\section{References}

1. Calisto KL, Camacho AC, Mittestainer FC, Carvalho BM, Guadagnini D, Carvalheira JB, Saad MJ. Diacerhein attenuates the inflammatory response and improves survival in a model of severe sepsis. Crit Care. 2012;16:R158.

2. Flores, et al. Obesity-induced increase in tumor necrosis factor-a leads to development of colon cancer in mice. Gastroenterology. 2012;143(3):741-53. e4.

3. Prada, et al. Selective modulation of the CAP/Cbl pathway in the adipose tissue of high fat diet treated rats. FEBS Lett. 2006;580(20):4889-94.

4. Flores, et al. Exercise Improves Insulin and Leptin Sensitivity in Hypothalamus of Wistar Rats. Diabetes. 2006;55:2554-61.

5. Ropelle, et al. A central role for neuronal adenosine 5'-monophosphateactivated protein kinase in cancer-induced anorexia. Endocrinology. 2007; 148(11):5220-9.

6. Ropelle, et al. A central role for neuronal AMP-activated protein kinase (AMPK) and mammalian target of rapamycin (mTOR) in high-protein diet-induced weight loss. Diabetes. 2008;57(3):594-605. 
7. Ropelle, et al. Acute exercise modulates the Foxo1/PGC-1a pathway in the liver of diet-induced obesity rats. J Physiol. 2009;587(Pt 9):2069-76.

8. Ropelle, et al. Central Exercise Action Increases the AMPK and mTOR Response to Leptin. PLoS One. 2008;3(12):e3856.

9. De Souza, et al. Acute exercise reduces hepatic glucose production through inhibition of the Fox01/HNF-4a pathway in insulin resistant mice. J Physiol. 2010;588(Pt 12):2239-53.

10. Oliveira, et al. Physical Exercise Reduces Circulating Lipopolysaccharide and TLR4 Activation and Improves Insulin Signaling in Tissues of DIO Rats. Diabetes. 2011;60(3):784-96.

11. Calisto, et al. Atorvastatin Improves Survival in Septic Rats: Effect on Tissue Inflammatory Pathway and on Insulin Signaling. PLoS One. 2010;5(12):e14232. 